Cahiers $d u$ MONDE RUSSE

\section{Cahiers du monde russe}

Russie - Empire russe - Union soviétique et États indépendants

$50 / 1 \mid 2009$

Écrits personnels. Russie XVIII $-\mathrm{XX}^{\mathrm{e}}$ siècles

\title{
Les journaux, des manuscrits uniques
}

\section{OpenEdition}

Journals

Édition électronique

URL : https://journals.openedition.org/monderusse/9152

DOI : 10.4000/monderusse. 9152

ISSN : $1777-5388$

\section{Éditeur}

Éditions de l'EHESS

\section{Édition imprimée}

Date de publication : 31 mars 2009

Pagination : 67-67

ISBN : 978-2-7132-2259-7

ISSN : $1252-6576$

Référence électronique

"Les journaux, des manuscrits uniques », Cahiers du monde russe [En ligne], 50/1 | 2009, mis en ligne le 01 janvier 2009, consulté le 06 septembre 2022. URL : http://journals.openedition.org/ monderusse/9152; DOI : https://doi.org/10.4000/monderusse.9152 


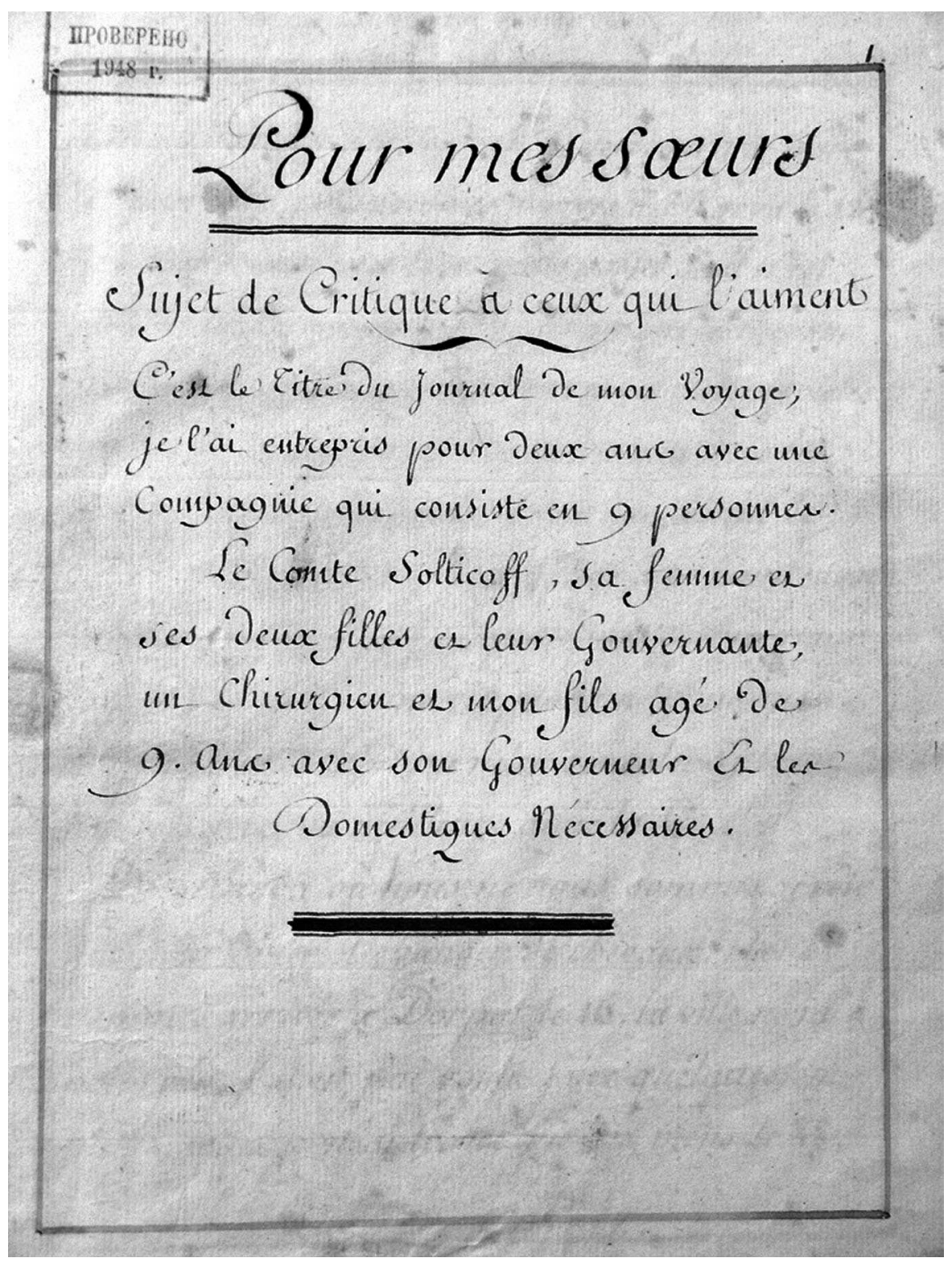

Fig. 1 - Baronne Natal'ja Mihajlovna Stroganova.

Incipit du Journal du 17 juillet 1780 au 30 juillet 1782, copie de main inconnue. Bibliothèque de l'université d'État de Tomsk, Département des manuscrits et livres rares.

Il s'agit du plus ancien des journaux russes féminins rédigés en français que nous avons pu répertorier. A-t-il été recopié à partir de notes de voyage, ou parce que l'écriture de la baronne était illisible? 


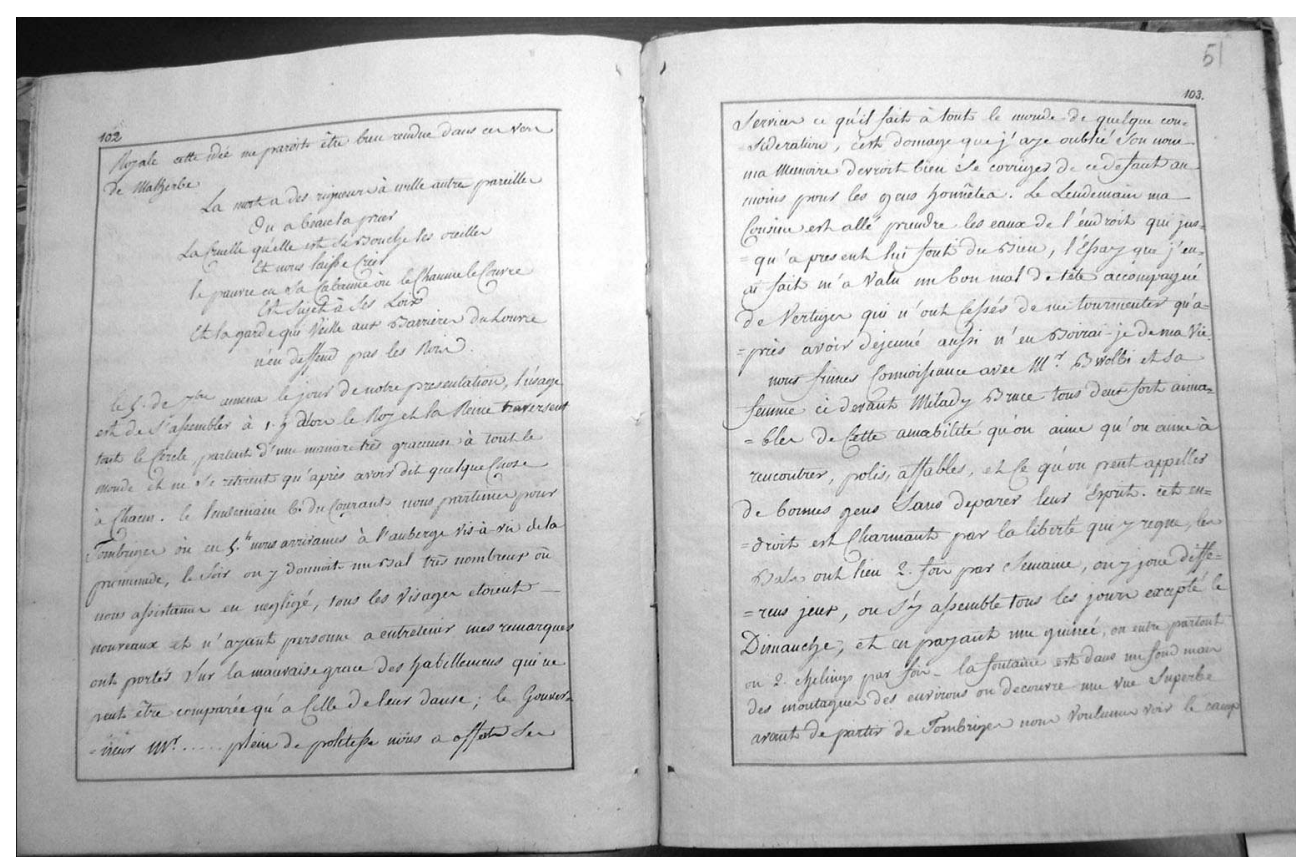

Fig. 2 - Baronne Natal'ja Mihajlovna Stroganova. P. 102-103 (f50v-51) du Journal du 17 juillet 1780 au 30 juillet 1782, copie de main inconnue. Bibliothèque de l'université d'État de Tomsk, Département des manuscrits et livres rares. Marge encadrant le texte dessinée à l'encre rouge. 


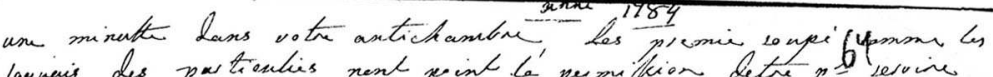

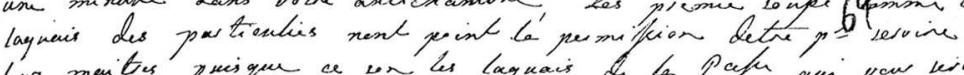

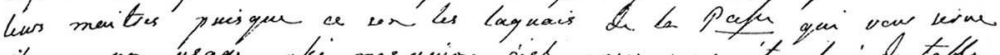

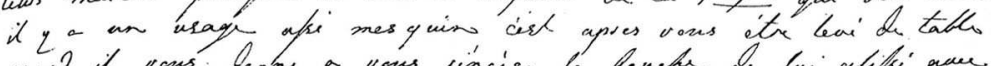

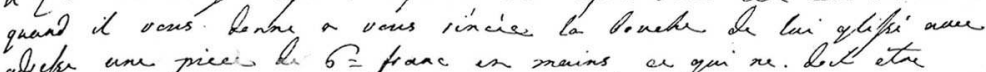

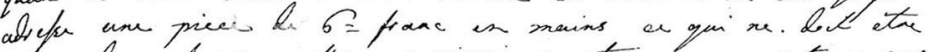

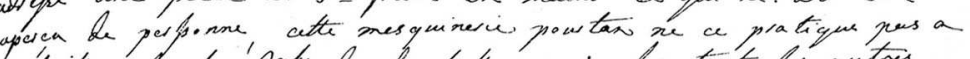

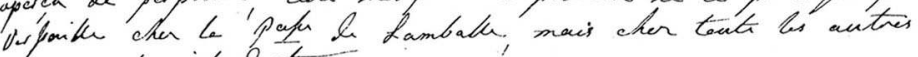
lanage at in to Duthe

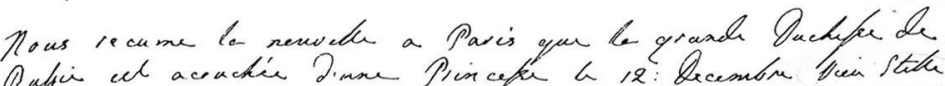

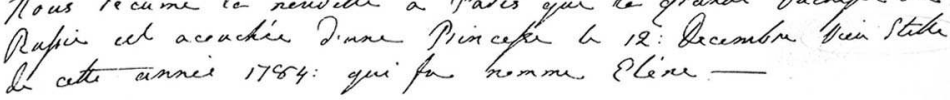

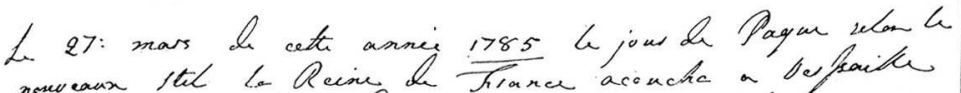

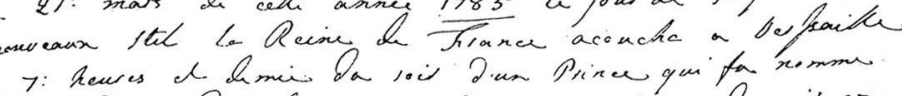

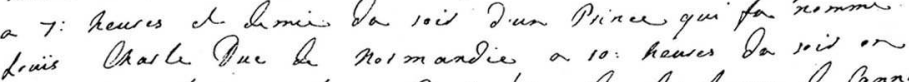

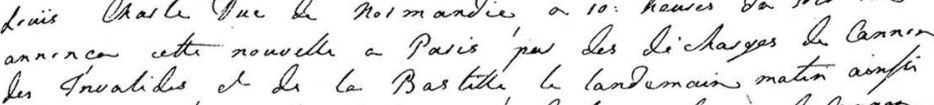

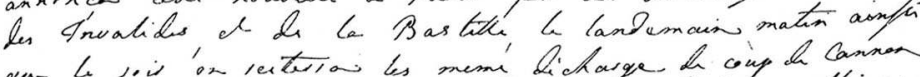

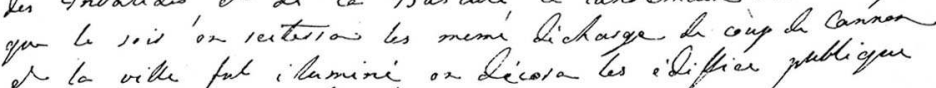

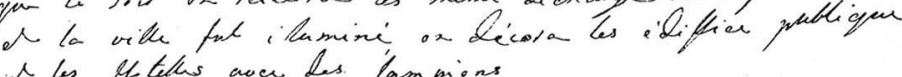

Le vardredie gin etrit. Le 1: Davrith Le Roi eat arvivin a 6: De nit acce pon corteger a Paries a compagnei de tous les

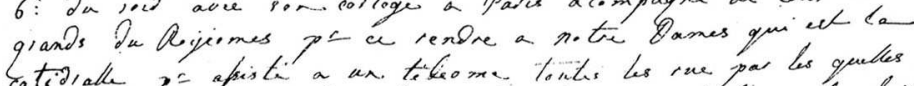

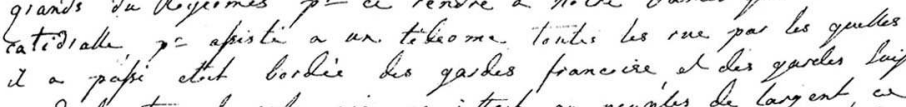

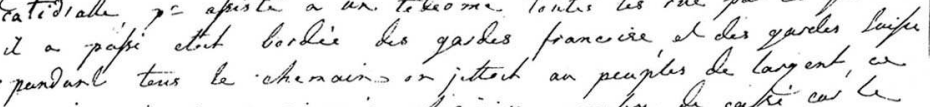

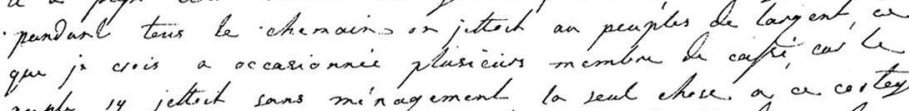

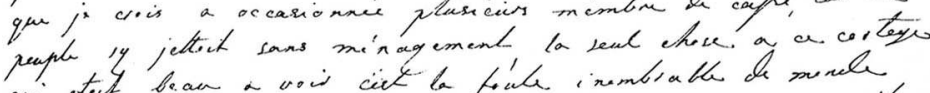

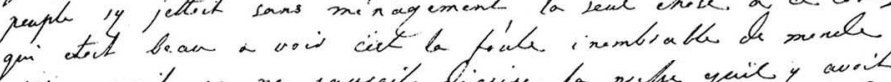

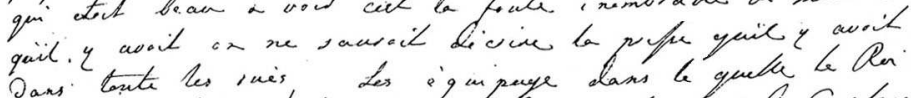

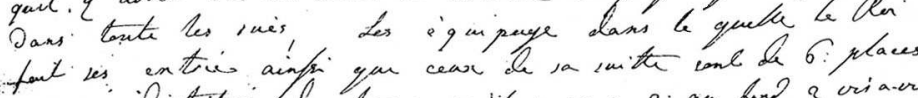

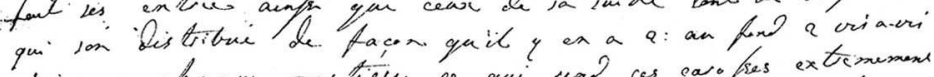

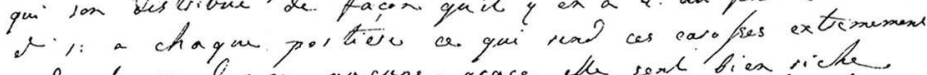
grand of $r y$ don ane ancure grace, the sont biex iche.

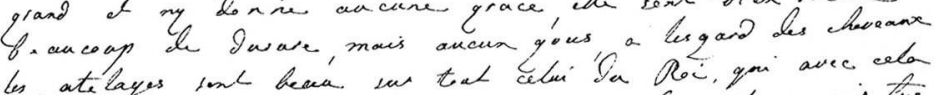

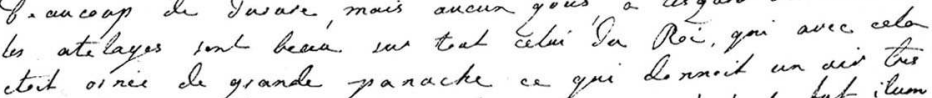

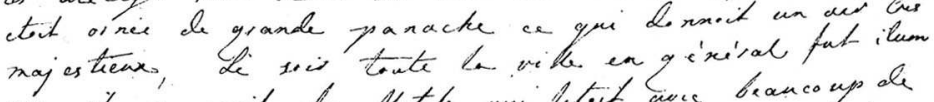

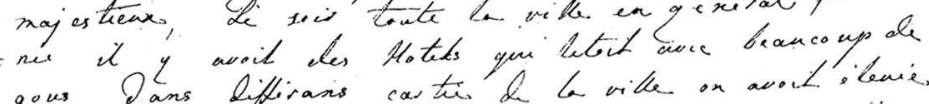

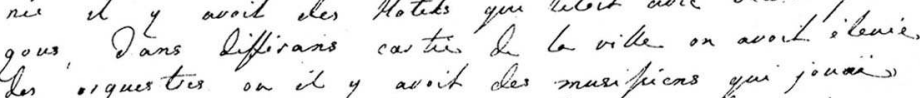

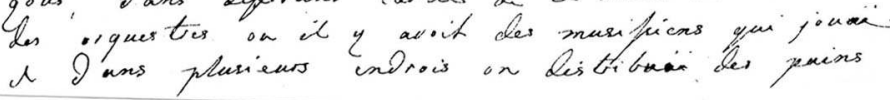

Fig. 3 - Princesse Natal'ja Petrovna Golicyna. Remarques sur mes voyages, autographe, 1783-1790, RGB, f. 64, carton 113, d. 1, 1. 64.

Le français de la princesse est fortement oralisé,

et ne se comprend souvent qu'en lisant le texte à haute voix. 


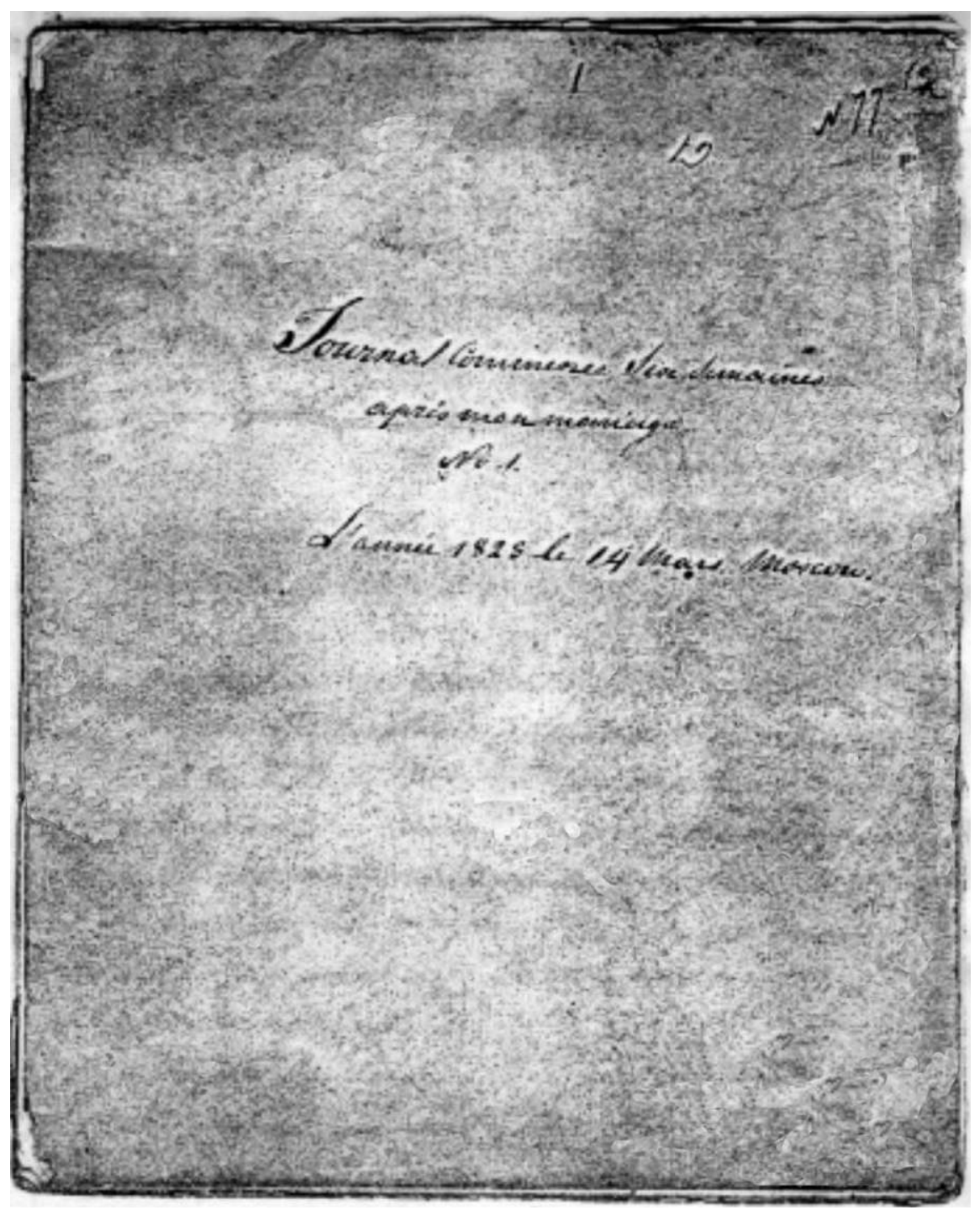

Fig. 4 - Princesse Elizaveta Aleksandrovna Šakhovskaja, née Muhanova. Page de titre de son Journal commencé six semaines après mon mariage. GARF, f. 1738, op. 1, n 8, 1. 1. Durant la longue période des fiançailles, Elizaveta a rédigé plusieurs journaux consacrés, et dédié, à son futur époux. Celui-ci, entrepris peu après le mariage, relate son tout récent bonheur, mais aussi quelques inquiétudes... 


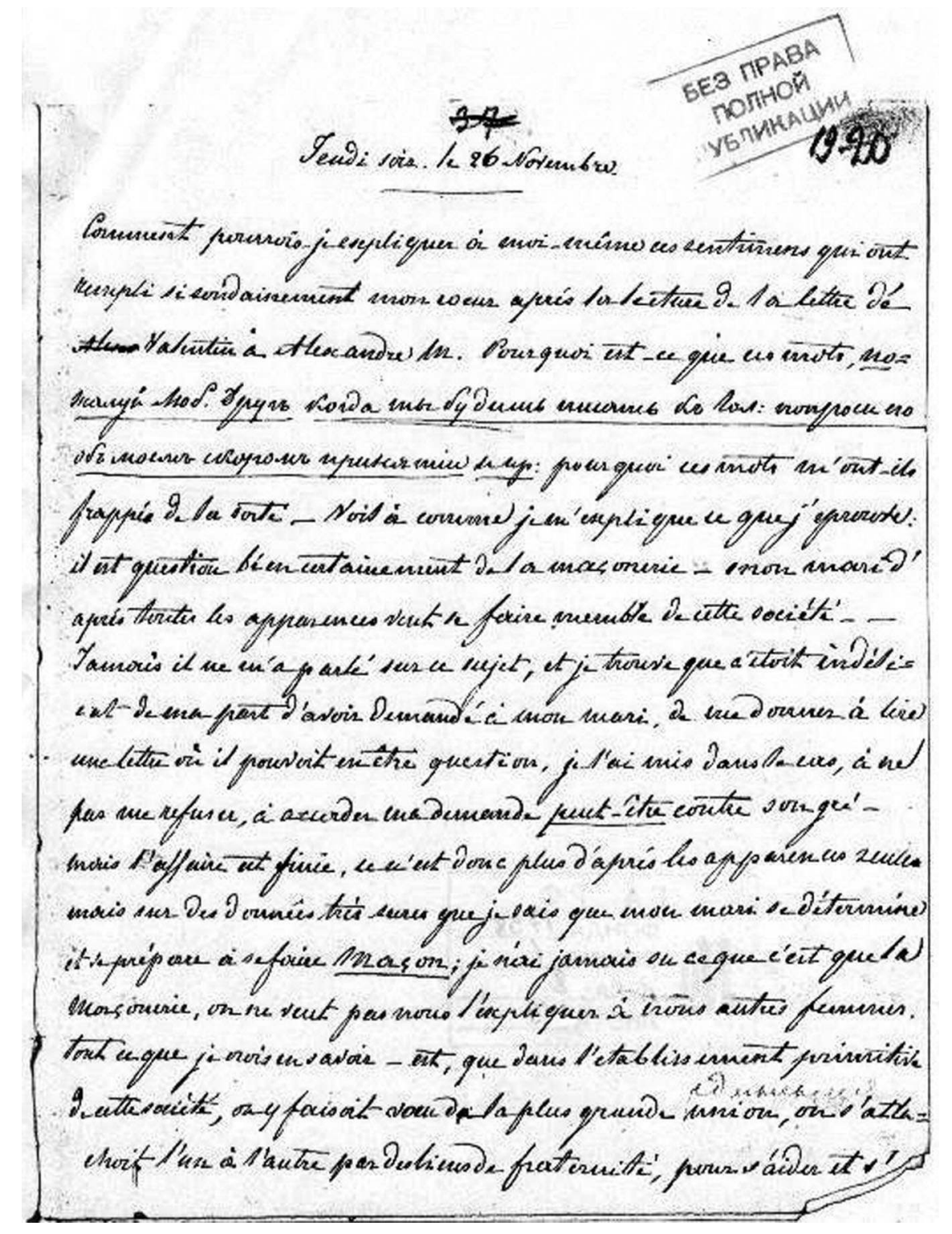

Fig. 5 - Princesse Elizaveta Aleksandrovna Šahovskaja, née Muhanova. Journal commencé six semaines après mon mariage. GARF, f. 1738, op. 1, n 8, 1. 19-20. Dans ce journal, Elizaveta relate les débuts de sa vie conjugale, et se plaint que son mari lui cache ses activités de franc-maçon. 


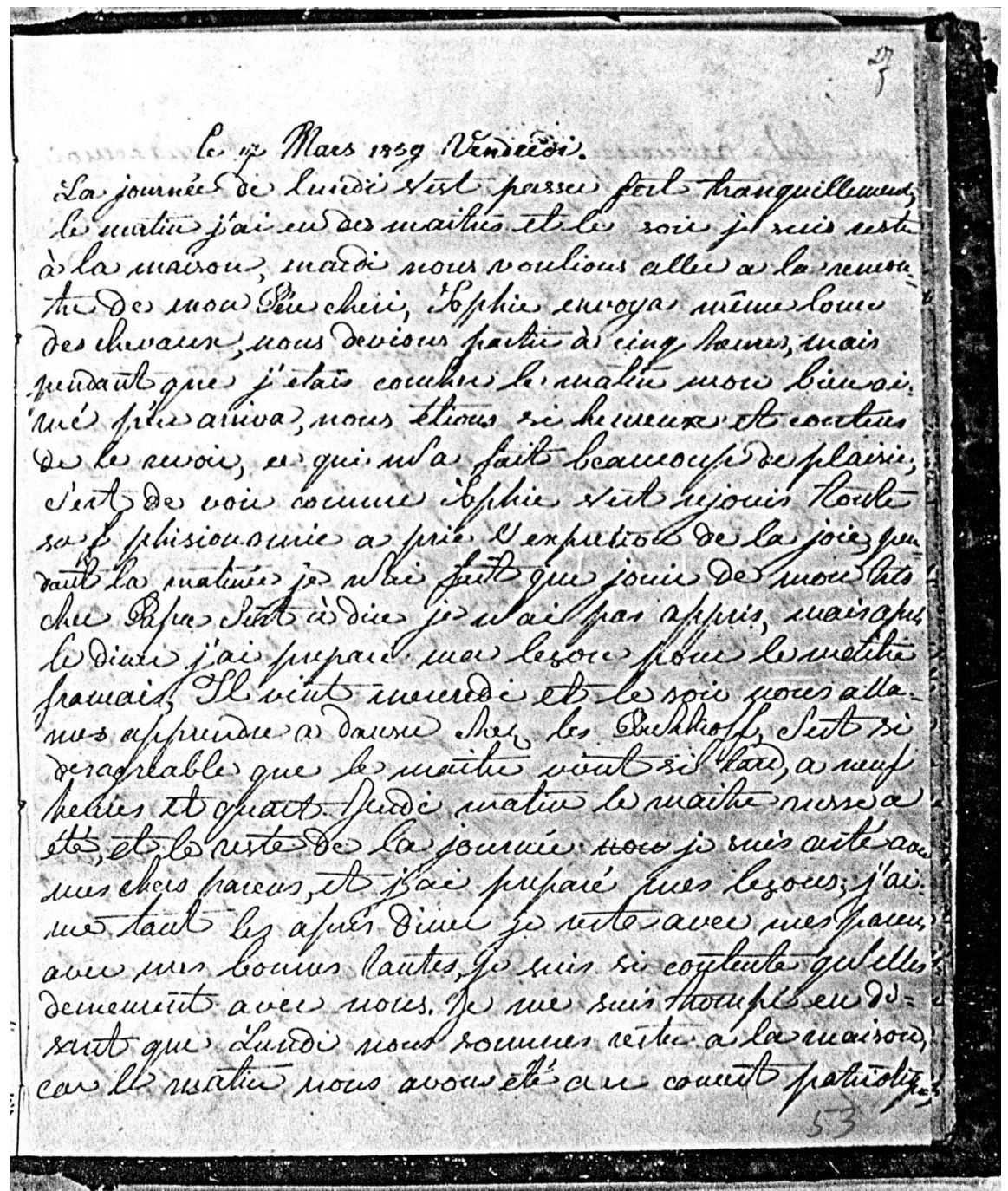

Fig. 6 - Princesse Natal'ja Valentinovna Šahovskaja (1825-1847), Journal du 20 décembre 1838 au 23 août 1840, autographe. IRLI, f. 334, d. 977, 1. 53.

Elle est la fille d'Elizaveta Aleksandrovna Sahovskaja, née Muhanova, et de Valentin Mihajlovic Šahovskoj. Trois journaux de sa main sont conservés, l'un à Moscou, les deux autres à Saint-Pétersbourg.

Ce journal est rédigé à l'âge de 13 ans, à l'occasion d'un voyage en Europe. 


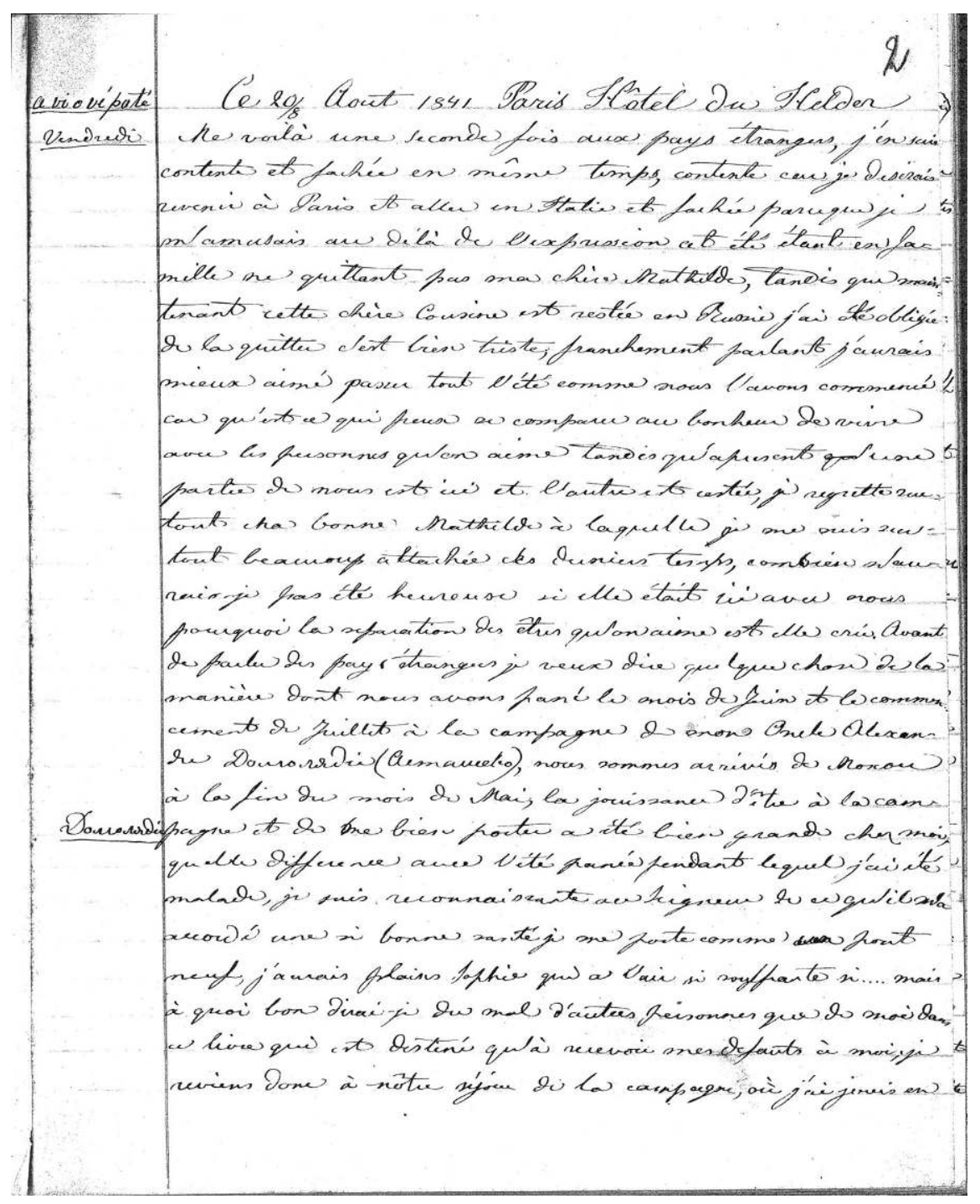

Fig. 7 - Princesse Natalija Valentinovna Šahovskaja, Journal du 20/8 août 1841 au 29/17 août 1842, autographe. RGALI, f. 1337, op. 1, d. 292, 1. 2. Ce deuxième journal, entrepris à l'âge de 15 ans, relate le second séjour en Europe. Comme l'illustration suivante - journal « parallèle » de sa cousine germaine Praskov’ja Mihajlovna Golynskaja, il présente les caractéristiques graphiques et spatiales du journal de voyage : soulignements des toponymes et anthroponymes, indications-repères en marge. 


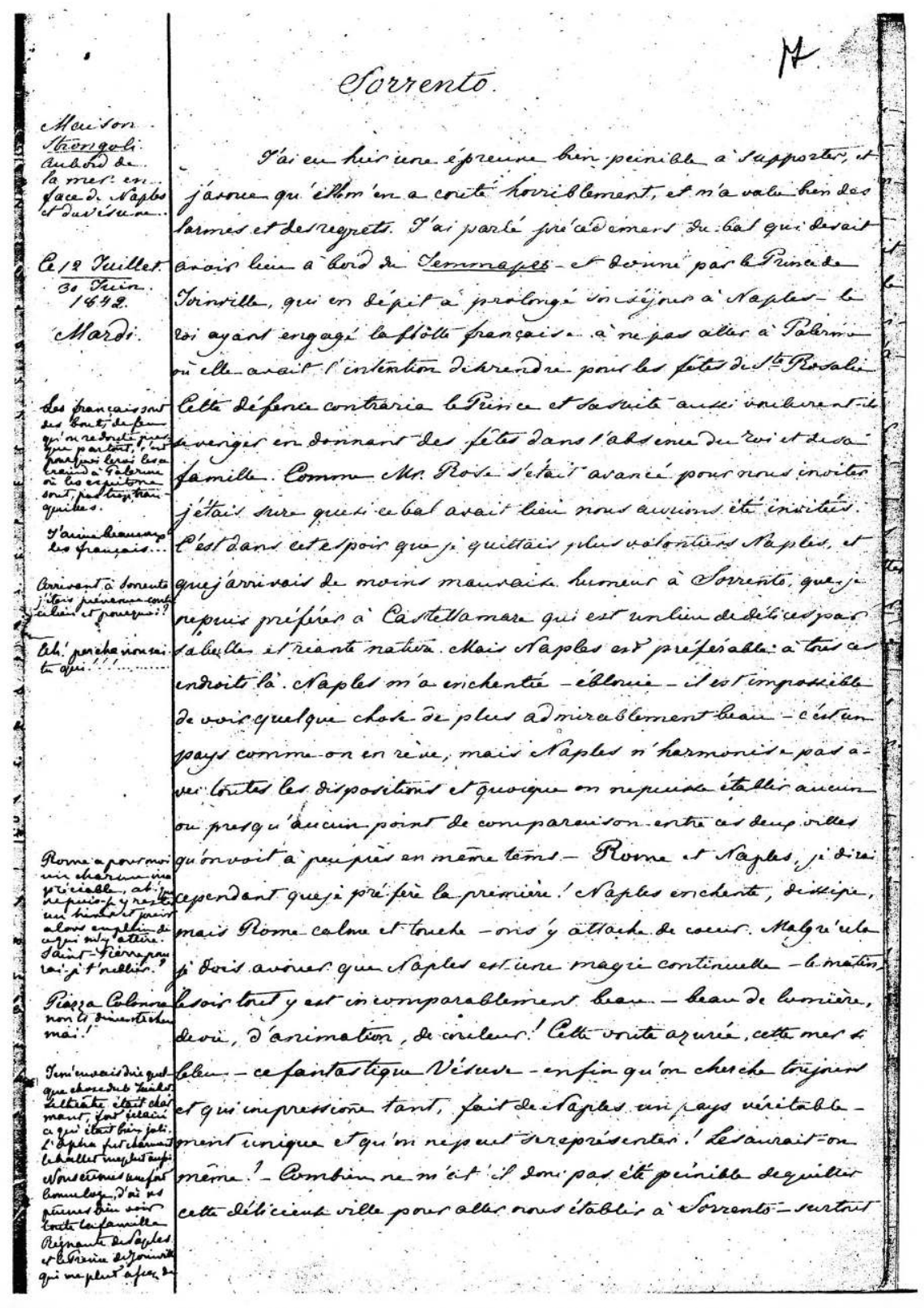

Fig. 8 - Praskov'ja Mihajlovna Golynskaja, Journal du 6 octobre 1841 au 11/23 octobre 1842, autographe. RGB, f. 336/2, carton 78, d. 2, 1. 17. Ce journal de voyage se présente sur des feuilles volantes de grand format, rassemblées en liasses en fonction des lieux visités. Il fourmille de détails, et permet de retracer l'itinéraire presque complet de ce voyage entrepris en famille. 


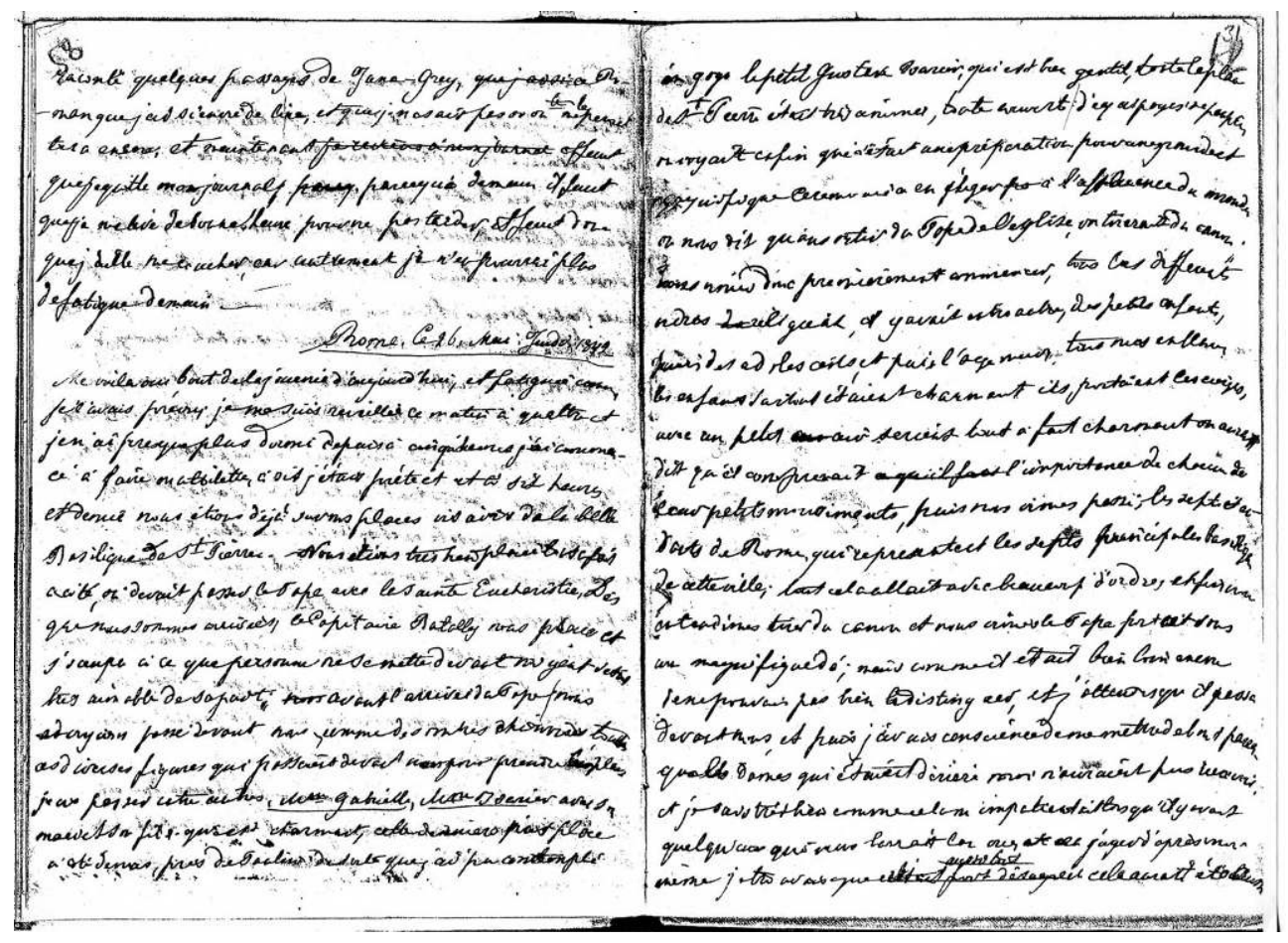

Fig. 9 - Sof'ja Aleksandrovna Murav'eva, Journal - Mai 1842, autographe, rédigé à Rome du 17 au 31 mai 1842. RGB, f. 336/2, carton 78, d. 3, 1. 30vº-31. Sof' ja est une autre des cousines qui participent au même voyage en France et en Italie. Il s'agit d'un carnet de petit format, où il est principalement question de ses tourments liés à une mystérieuse «faute». 

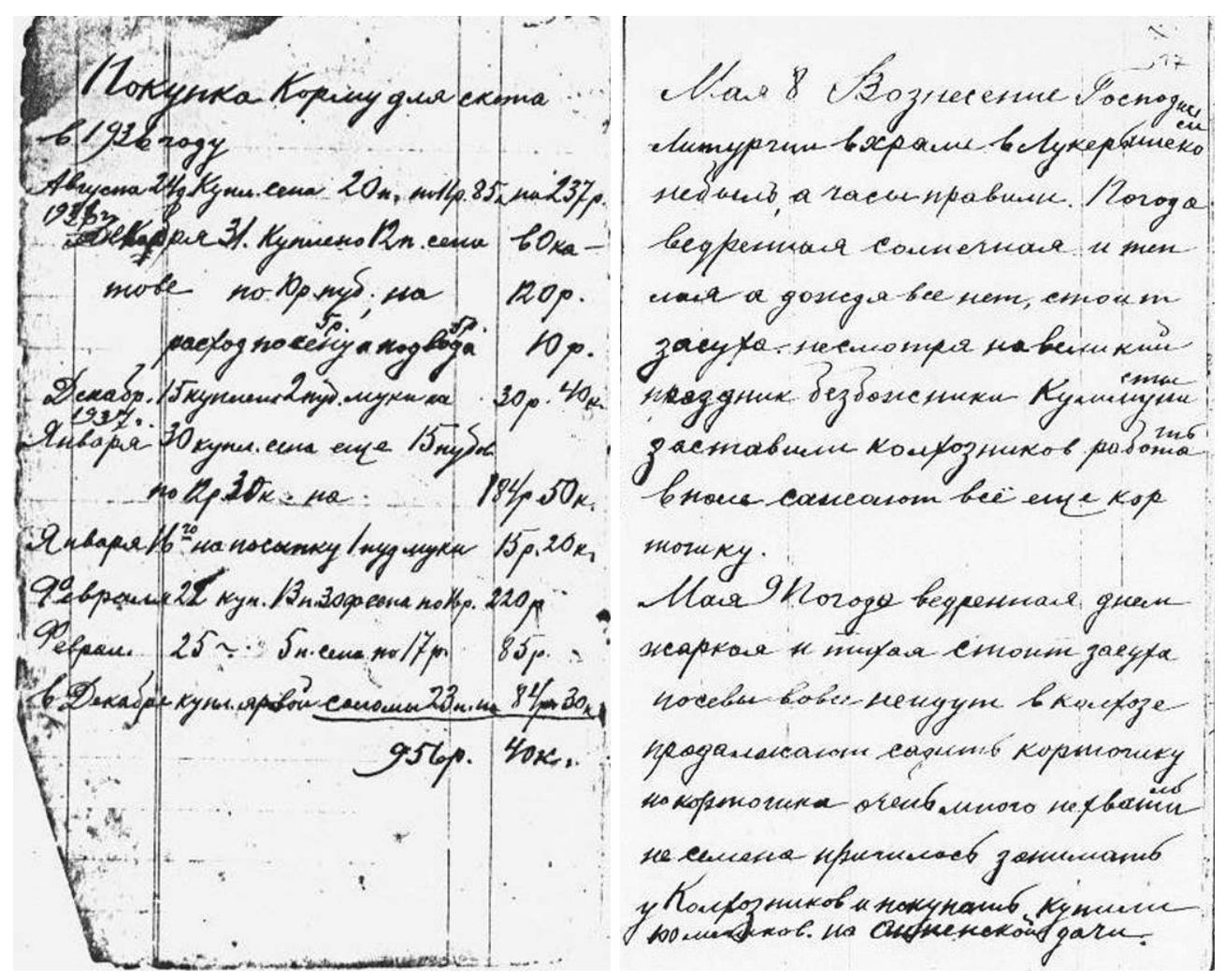

Fig. 10 - Il y a celles du paysan lettré, Ignatij Frolov : rapide et comme fonctionnelle, en habit de tous les jours quand il faut noter les dépenses pour le bétail ; soignée, comme si elle devait mettre ses habits du dimanche pour poser les majuscules d'importance : que ce soit le Jour du Seigneur, la Pomme de Terre, ou le Temps qu'il fait.

Ces majuscules disent un rapport au monde : Dieu, qui a créé la Nature, ne les « ordonne »-t-il pas ?

(Section des manuscrits de la bibliothèque Lenin de Moscou, f. 2418, n. 1283, ed. hr. 13) 


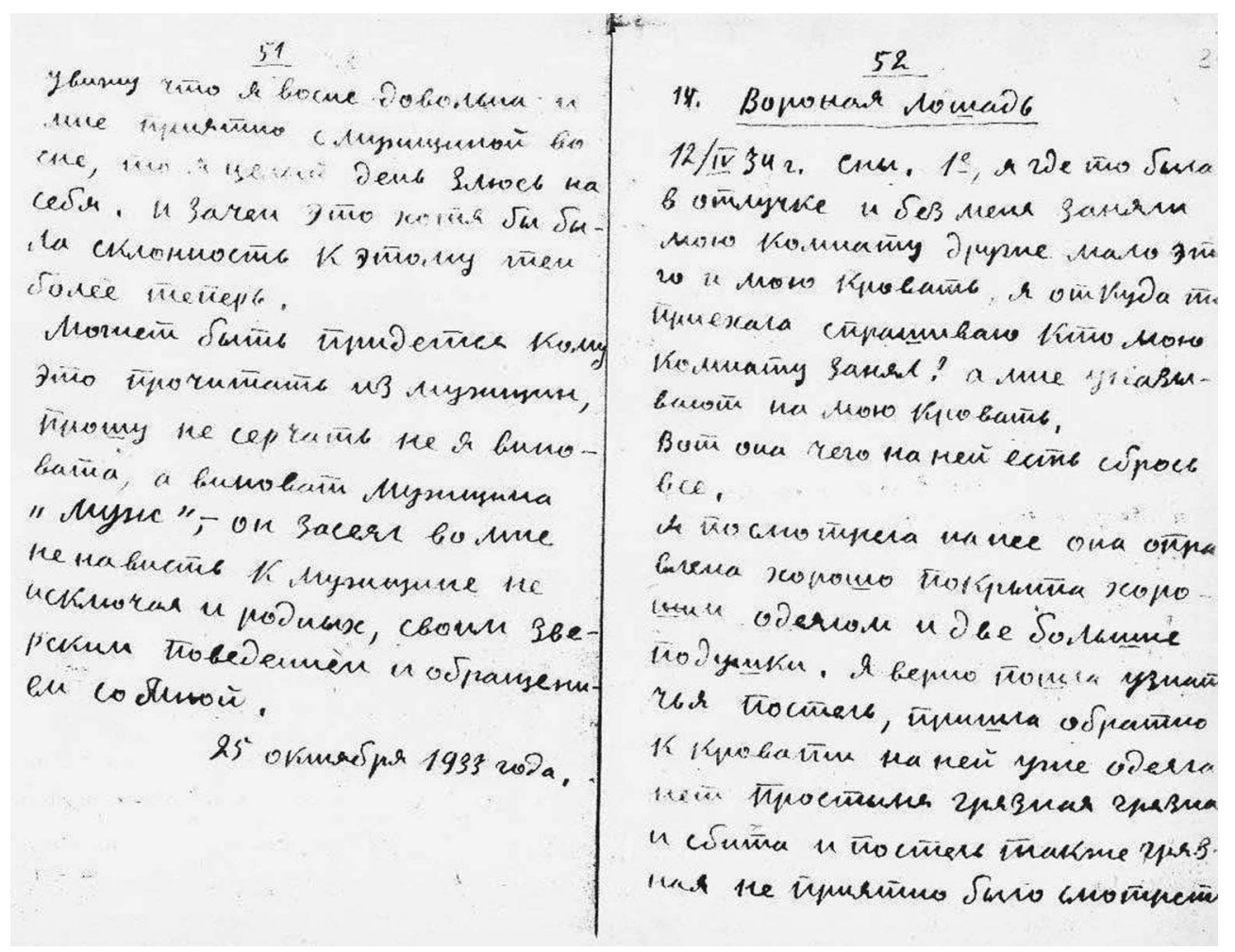

Fig. 11 - Il y a celle de A.G. Korevanova, membre de l'Union des écrivains de l'Oural, ex-ouvrière : toujours égale mais comme haletante : on ne sait si sa scriptio continua souvent ignorante de la ponctuation témoigne d'une oralité pas entièrement battue en brèche par un apprentissage tout neuf de l'écrit ou d'un désir fébrile de ne pas perdre, par exemple, le goût, le bonheur nostalgiques de la miche de pain blanc dévorée en rêve ou du baiser si doux déposé par un mari de rêve... Car A.G. Korevanova. consigne, date, numérote et titre ses songes comme autant de petites nouvelles. Et ces petites nouvelles brouillent, parfois de façon saisissante, la frontière entre rêve et réalité : ô l'angoisse de la mort pressentie de Gorkij... en avril 1936 ! (Journal recueilli dans le cadre de la recherche « Journaux intimes et Terreur ») 


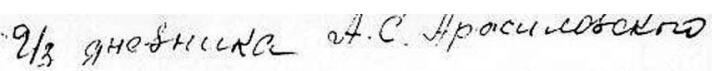

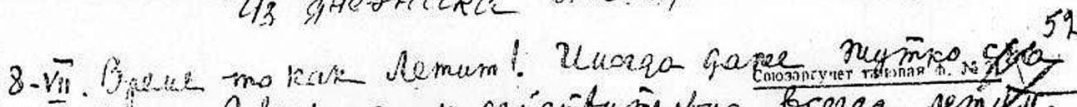

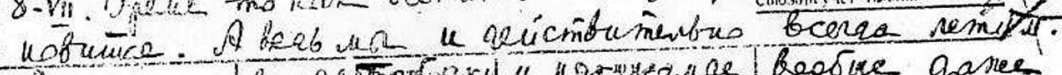

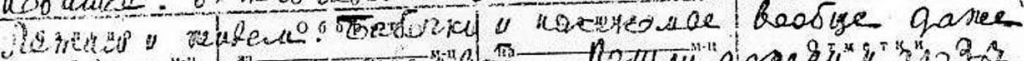
- Tre to

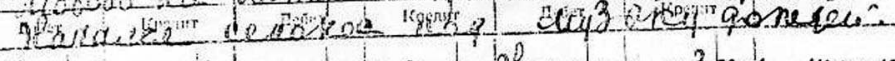

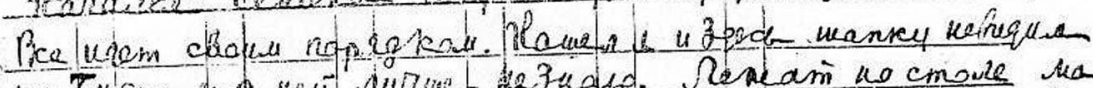

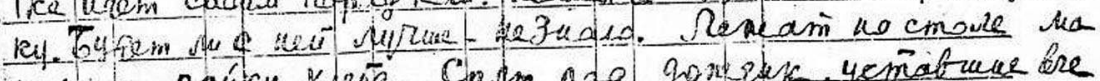

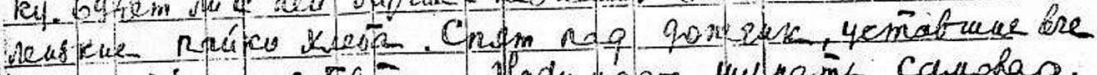

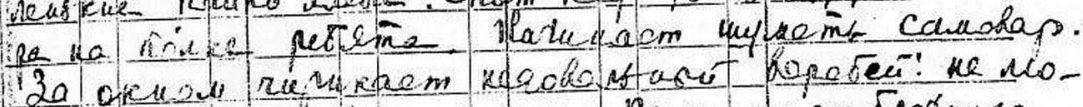

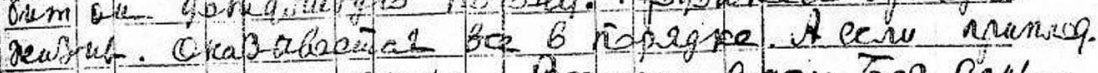

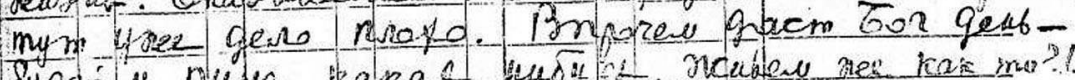

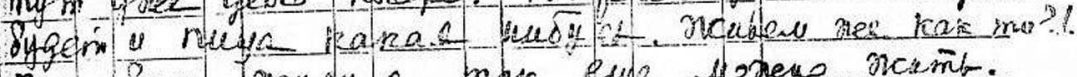

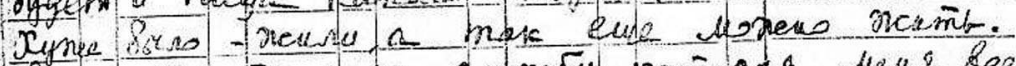

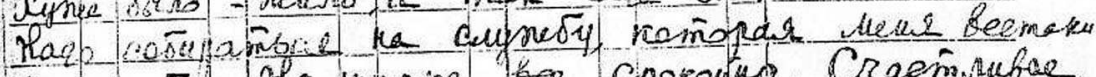

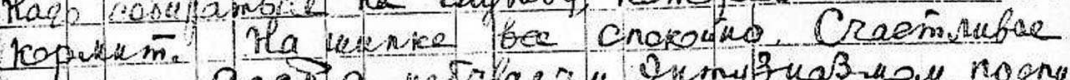

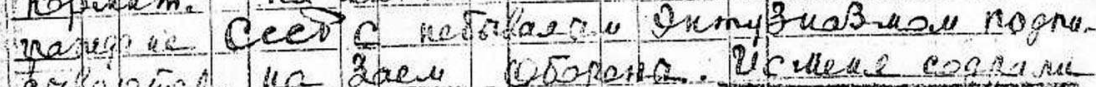

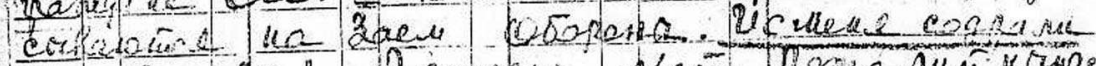

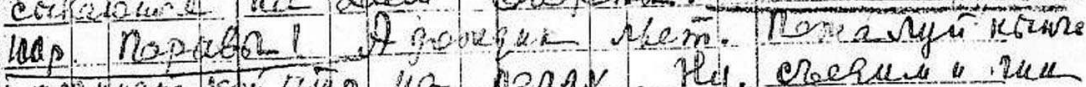

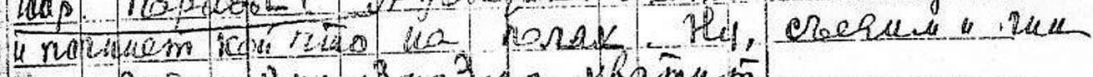

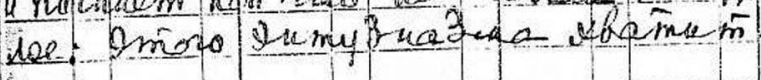

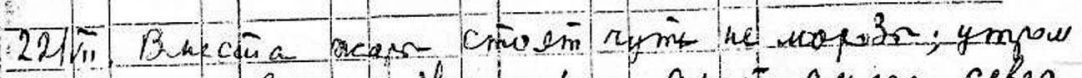

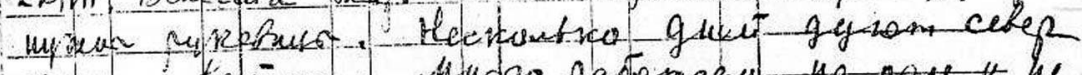

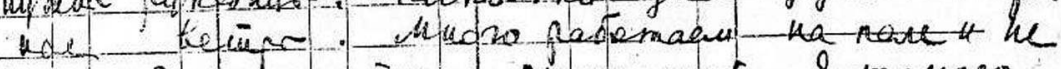

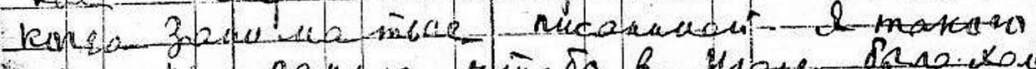

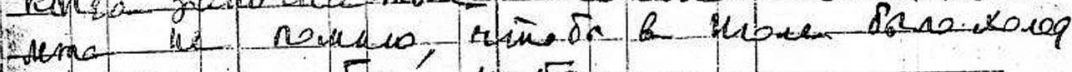

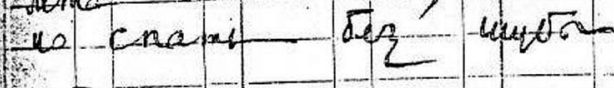

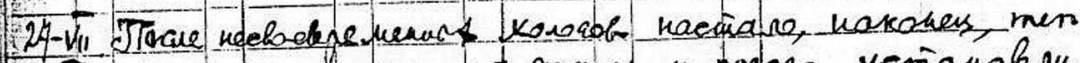

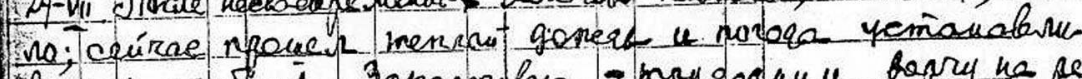

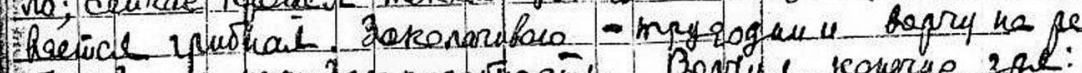

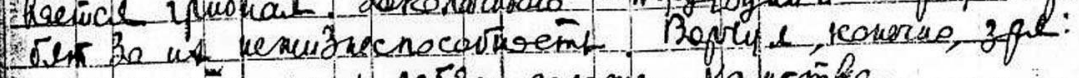

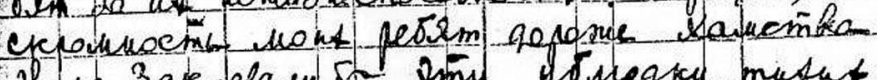

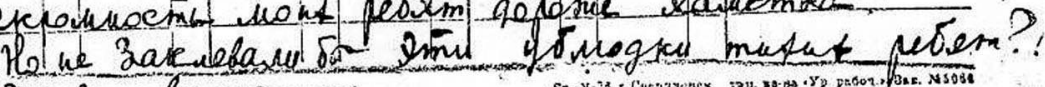
Deulen brporouest.

Fig. 12a - Il y a celle d'Andrej Aržilovskij, tout juste libéré du camp, qui dit l'espoir de devenir invisible aux yeux des « organes ». Mais il a aussi celle de l'Inquisiteur, sèche, raide et violente, sans pleins et déliés : elle se contente a posteriori de souligner les propos délictueux. 


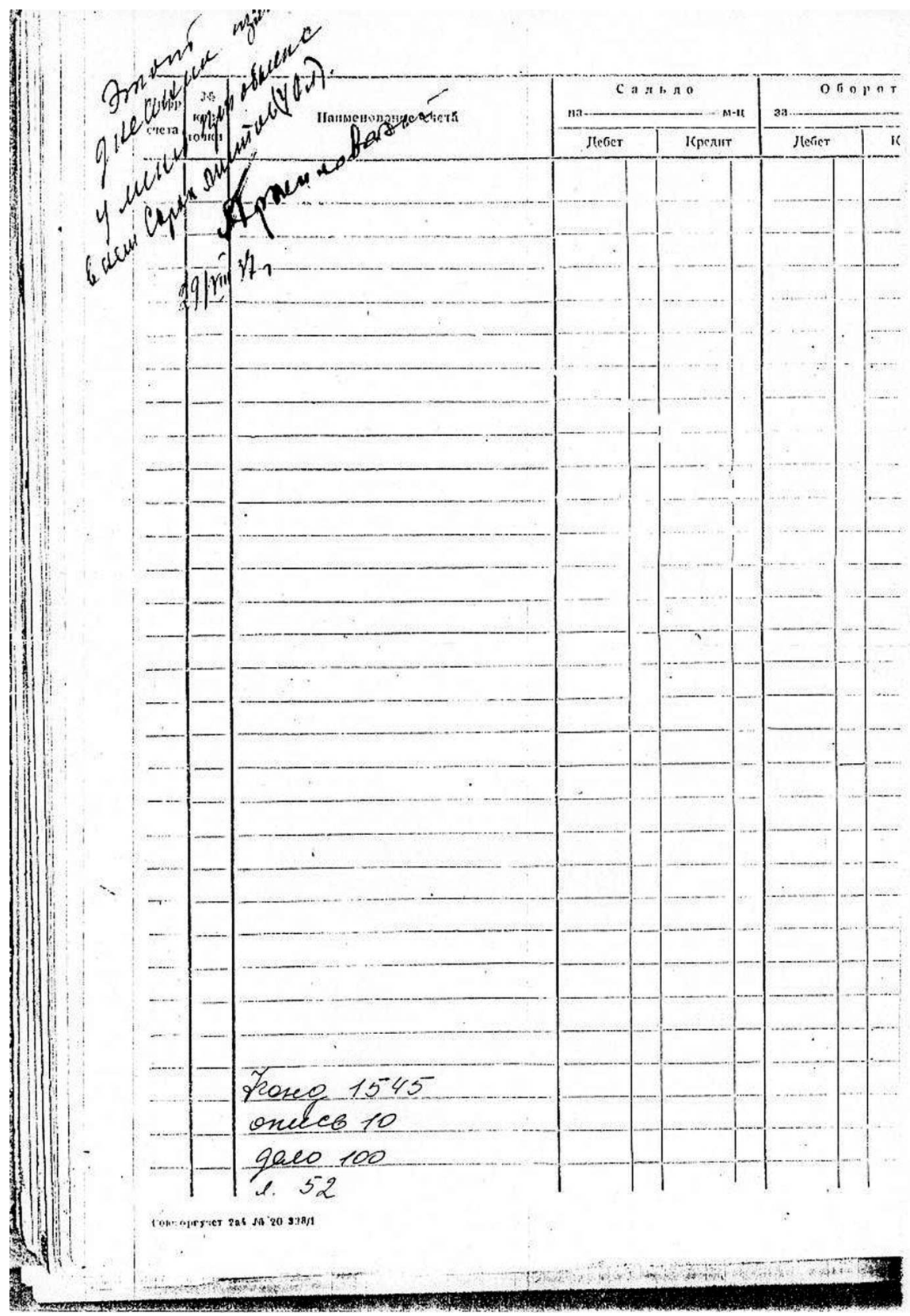

Fig. 12b - L'espoir, on l'aura compris, sera fusillé. Sept jours après que l'auteur eût apposé ces lignes, sans doute dictées : «Ce Journal m'a été confisqué au cours d'une perquisition \#il contient quarante pages (40 p.). Aržilovskij. Le 29/VIII-37 ». (Archives d'État de Sverdlovsk, f. 1545, op. 10, d. 100) 
LIRE L'ÉCRIT, OUI MAIS L'ÉCRITURE..

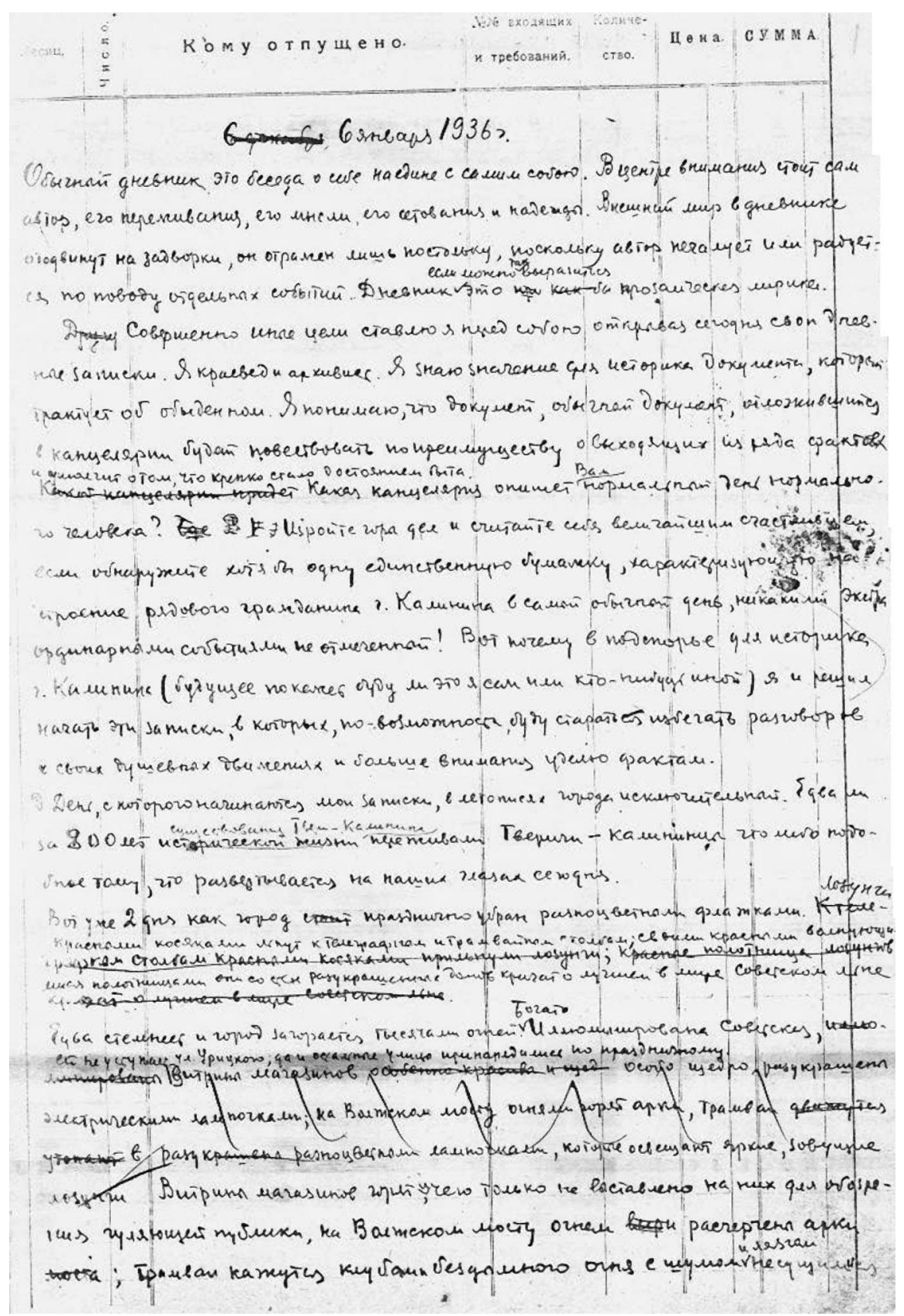

Fig. 13 - Il y a celle de Nikolaj Žuravlev, archiviste en chef, qui, en inaugurant son Journal ne craint pas les ratures : sa vie consignée ne sera au demeurant que « ratures ». À l'inverse des intentions affichées de ne pas laisser libre plume à ses états d'âme, le livre de compte « détourné » (pénurie de papier oblige) nous dira essentiellement l'attente de sa femme, volage, qui ne rentrera pas dormir ; l'attente de voir publiés des articles qui ne le seront jamais ; l'attente d'être réintégré au sein du Parti. (Archives d'État de Tver', f. R-452) 